\title{
Association Between Vitamin D Insufficiency and Metabolic Syndrome in Patients With Psychotic Disorders
}

\author{
Taeyoung Yoo', Wonsuk Choi ${ }^{2}$, Jin-Hee Hong ${ }^{3}$, Ju-Yeon Lee ${ }^{1,3,4}$, Jae-Min Kim¹, II-Seon Shin', \\ Soo Jin Yang ${ }^{5}$, Paul Amminger ${ }^{6}$, Michael Berk ${ }^{6,7}$, Jin-Sang Yoon ${ }^{1}$, and Sung-Wan Kim ${ }^{1,3,4} \bowtie$ \\ 1'Department of Psychiatry, Chonnam National University Medical School, Gwangju, Republic of Korea \\ ${ }^{2}$ Graduate School of Medical Science and Engineering, Korea Advanced Institute of Science and Technology, Daejeon, Republic of Korea \\ ${ }^{3}$ Mindlink, Gwangju Bukgu Community Mental Health Center, Gwangju, Republic of Korea \\ ${ }^{4}$ Gwangju Mental Health Commission and Gwangju Bukgu Community Mental Health Center, Gwangju, Republic of Korea \\ ${ }^{5}$ Department of Food and Nutrition, Seoul Women's University, Seoul, Republic of Korea \\ ${ }^{6}$ Orygen, The National Centre of Excellence in Youth Mental Health and the Department of Psychiatry, The University of Melbourne, \\ Melbourne, Australia \\ ${ }^{7}$ IMPACT Strategic Research Centre, School of Medicine, Deakin University, Geelong, Australia
}

Objective This study examined the association between vitamin $\mathrm{D}$ and metabolic syndrome in patients with psychotic disorders.

Methods The study enrolled 302 community-dwelling patients with psychotic disorders. Sociodemographic and clinical characteristics, including blood pressure, physical activity, and dietary habit were gathered. Laboratory examinations included vitamin D, lipid profile, fasting plasma glucose, HbA1c, liver function, and renal function. Vitamin D insufficiency was defined as $<20 \mathrm{ng} / \mathrm{mL}$. Clinical characteristics associated with vitamin D insufficiency were identified.

Results Among the 302 participants, 236 patients (78.1\%) had a vitamin D insufficiency and 97 (32.1\%) had metabolic syndrome. Vitamin D insufficiency was significantly associated with the presence of metabolic syndrome $(\mathrm{p}=0.006)$ and hypertension $(\mathrm{p}=0.017)$. Significant increases in triglycerides and alanine transaminase were observed in the group with a vitamin $\mathrm{D}$ insufficiency ( $\mathrm{p}=0.002$ and 0.011 , respectively). After adjusting for physical activity and dietary habit scores, vitamin D insufficiency remained significantly associated with metabolic syndrome and hypertension.

Conclusion Vitamin D insufficiency was associated with metabolic syndrome and was particularly associated with high blood pressure, although the nature, direction and implications of this association are unclear.

Psychiatry Investig 2018;15(4):396-401

Key Words Vitamin D, Hypertension, Metabolic syndrome, Schizophrenia, Psychotic disorder.

\section{INTRODUCTION}

Vitamin D affects various parts of the body, including the musculoskeletal, cardiovascular, and neurocognitive systems. It is also related to mental health. Low vitamin D level is associated with various psychiatric illnesses, including depression, dementia, and autism spectrum disorder. ${ }^{1-4}$ Vitamin D levels are low in patients with schizophrenia. In one study, the prev-

Received: June 4, 2017 Revised: July 16, 2017

Accepted: August 30, 2017

$\square$ Correspondence: Sung-Wan Kim, MD, PhD

Department of Psychiatry, Chonnam National University Medical School, 160 Baekseo-ro, Dong-gu, Gwangju 61469, Republic of Korea

Tel: +82-62-220-6148, Fax: +82-62-225-2351, E-mail: swkim@chonnam.ac.kr

(a) This is an Open Access article distributed under the terms of the Creative Commons Attribution Non-Commercial License (http://creativecommons.org/licenses/bync/4.0) which permits unrestricted non-commercial use, distribution, and reproduction in any medium, provided the original work is properly cited. alence of vitamin deficiency/insufficiency was $92.5 \%$ in patients in the acute phase of schizophrenia. ${ }^{5}$ The level of vitamin $\mathrm{D}$ also affects symptom severity in patients with schizophrenia. ${ }^{6.7}$ Levels of vitamin $\mathrm{D}$ in utero predict later risk for schizophrenia. ${ }^{8}$

Low vitamin D level is independently associated with allcause mortality in the general population. ${ }^{9}$ In particular, low vitamin $\mathrm{D}$ is associated with cardiovascular disease. ${ }^{10} \mathrm{In}$ a $10-$ year follow-up study, male patients without previous cardiovascular disease and vitamin $\mathrm{D}$ deficiency $[25(\mathrm{OH}) \mathrm{D}<15 \mathrm{ng} /$ $\mathrm{mL}$ ] exhibited a twofold increase in the rate of myocardial infarction. ${ }^{11}$ Participants in the Framingham Offspring Study who had no history of cardiovascular disease but a severe vita$\min \mathrm{D}$ deficiency $[25(\mathrm{OH}) \mathrm{D}<10 \mathrm{ng} / \mathrm{mL}]$ had a hazard ratio of 1.8 (95\% confidence interval, 1.05-3.08) for developing new cardiovascular disease after a 5-year follow-up compared to 
participants who had higher levels of $25(\mathrm{OH}) \mathrm{D}(>15 \mathrm{ng} / \mathrm{mL})$, although the direction of the association remains uncertain. ${ }^{10}$

However, evidence demonstrating an association between vitamin $\mathrm{D}$ and physical health in patients with schizophrenia is scarce. Patients with schizophrenia die 10-20 years earlier than the general population. ${ }^{7}$ This premature mortality is attributed to high comorbid physical illnesses, including cardiovascular disease and metabolic syndrome. ${ }^{12,13}$ Thus, it is important to understand the effect of vitamin D on the physical health of patients with a psychotic disorder.

Vitamin D levels vary according to ethnicity. They were shown to be relatively high in Caucasians compared to those in Mexican-Americans and African-Americans. ${ }^{14}$ In addition, vitamin $\mathrm{D}$ level also varies from region to region. ${ }^{15}$ Asians, including Japanese and Koreans, show low vitamin D levels during summer and winter compared to people in other countries. ${ }^{16,17}$ Thus, vitamin D levels must be studied in various regions and ethnicities. In this study, we investigated the relationship between vitamin D level and metabolic syndrome in Korean patients with psychotic disorders.

\section{METHODS}

\section{Participants}

The present study used the data set from Gwangju Comprehensive Health Inspection for Mental Illness, which evaluated the physical health of patients with mental illness (psychotic and mood disorders) treated in community mental health centers in Gwangju, South Korea. The present study used data from patients who were treated for a psychotic disorder and excluded patients with a mood disorder. Of the 386 participants in the parent study, 302 with a psychotic disorder were included in the present study, of which 248 (82.1\%) had schizophrenia, 36 (11.9\%) had schizoaffective disorder, and $18(6.0 \%)$ had other specified schizophrenia spectrum disorder. This study was conducted from November 2015 to January 2016 and was approved by Chonnam National University Hospital's Institutional Review Board (CNUH-2015254). All subjects provided written informed consent before participating.

\section{Measures}

Basic demographic and clinical information was obtained from medical records and case managers and included psychiatric diagnoses, treatment duration, prescribed medications and dosages, depressive symptoms, physical activities, and dietary habits. Risperidone-equivalent doses were calculated to assess dose-dependent drug effects. ${ }^{18}$

The Clinical Global Impression (CGI) Scale was administered by case managers to evaluate global symptom severity. ${ }^{19}$
Depressive symptoms were measured by four items from the Center for Epidemiological Studies Depression Scale (bothered by things, poor appetite, feel blue, and feel depressed). ${ }^{20}$ Physical activity was measured by three items from the International Physical Activity Questionnaire (IPAQ)-Short Form (vigorous physical activity, moderate physical activity, and walking). ${ }^{21}$ Physical activity was determined by the type of exercise and time according to the IPAQ scoring protocol. ${ }^{22}$ Dietary habits were evaluated with the dietary guidelines published by the Korean Ministry of Health and Welfare. ${ }^{23}$ The dietary questionnaire consisted of three subcategories including five items for diet regularity, six items for a balanced diet, and nine items for unhealthy diet and habits. In the balanced diet category, the dairy intake item was also used as a proxy variable for vitamin $\mathrm{D}$ intake. We asked how many times participants took milk and dairy products every week.

Fasting venous blood samples were obtained to assess vitamin D levels; lipid profiles including high-density-lipoprotein (HDL) cholesterol, low-density-lipoprotein cholesterol, triglycerides, and total cholesterol; fasting blood glucose (FBG); glycated hemoglobin, liver function tests including aspartate aminotransferase (AST), alanine transaminase (ALT), and gamma-glutamyltransferase; renal function tests, including blood urea nitrogen and creatinine; and prolactin. Blood pressure including systolic blood pressure and diastolic blood pressure was also measured. Body mass index was calculated as weight $/$ height ${ }^{2}\left(\mathrm{~kg} / \mathrm{m}^{2}\right)$.

Metabolic syndrome was diagnosed with the definitions of the modified ATP III for Korea (three or more of the following five criteria): abdominal obesity, defined as a waist circumference $\geq 90 \mathrm{~cm}$ in men and $\geq 85 \mathrm{~cm}$ in women ${ }^{24}$; serum triglycerides $\geq 150 \mathrm{mg} / \mathrm{dL}(1.7 \mathrm{mmol} / \mathrm{L})$ or drug treatment for elevated triglycerides; serum HDL cholesterol $<40 \mathrm{mg} / \mathrm{dL}$ (1 $\mathrm{mmol} / \mathrm{L})$ in men and $<50 \mathrm{mg} / \mathrm{dL}(1.3 \mathrm{mmol} / \mathrm{L})$ in women or drug treatment for low HDL cholesterol; blood pressure $\geq 130$ / $85 \mathrm{~mm} \mathrm{Hg}$ or drug treatment for elevated blood pressure; and $\mathrm{FPG} \geq 100 \mathrm{mg} / \mathrm{dL}$ ( $5.6 \mathrm{mmol} / \mathrm{L}$ ) or drug treatment for elevated blood glucose.

\section{Statistical analysis}

The participants were categorized into two groups according to vitamin $\mathrm{D}$ level. Vitamin D insufficiency was defined as $<20 \mathrm{ng} / \mathrm{mL}$ (equivalent to $<50 \mathrm{nmol} / \mathrm{L}$ ) and a serum level $\geq 20$ $\mathrm{ng} / \mathrm{mL}$ (equivalent to $\geq 50 \mathrm{nmol} / \mathrm{L}$ ) was considered optimal. ${ }^{25}$

Comparisons of demographic and clinical data according to the presence of vitamin $\mathrm{D}$ insufficiency were conducted with the $\chi^{2}$ test, independent $t$-test, or Mann-Whitney U-test, as appropriate. We examined the relationship between serum vitamin D insufficiency and metabolic syndrome using logistic regression analysis after controlling for physical activity and 
dietary habits. The statistical analysis was performed using SPSS for Windows ver. 23.0 (IBM Corp., Armonk, NY, USA). All statistical tests were two-sided, and the $\alpha$-level for statistical significance was 0.05 .

\section{RESULTS}

Among the 302 participants, 168 (55.6\%) were males and 134 were females. Their mean age was $40.7 \pm 12.0$ years (range
18-82 years) and mean duration of illness was $14.5 \pm 10.0$ years. Mean vitamin D level was $15.5 \pm 6.4 \mathrm{ng} / \mathrm{mL}$, and 236 patients (78.1\%) had a vitamin D insufficiency ( $<20 \mathrm{ng} / \mathrm{mL})$. Ninetyseven patients $(32.1 \%)$ met the criteria for metabolic syndrome. Vitamin D level was significantly lower in patients with metabolic syndrome than in those without metabolic syndrome $(13.1 \pm 5.0 \mathrm{ng} / \mathrm{mL}$ vs. $16.6 \pm 6.7 \mathrm{ng} / \mathrm{mL}$; $\mathrm{t}=4.616, \mathrm{p}<0.001)$.

Table 1 shows the demographic and clinical characteristics according to the presence of vitamin D insufficiency. Age, sex,

Table 1. Baseline demographic and clinical characteristics according to vitamin D level

\begin{tabular}{|c|c|c|c|}
\hline & \multicolumn{2}{|c|}{ Vitamin D level } & \multirow{2}{*}{ p-value } \\
\hline & $<20 \mathrm{ng} / \mathrm{mL}, \mathrm{N}=236(78.1 \%)$ & $\geq 20 \mathrm{mg} / \mathrm{mL}, \mathrm{N}=66(21.9 \%)$ & \\
\hline \multicolumn{4}{|l|}{ Sociodemographic characteristics } \\
\hline Sex, male (\%) & $128(54.2)$ & $40(60.6)$ & 0.402 \\
\hline Age, mean (SD), years & $41.0(12.0)$ & $40.0(12.1)$ & 0.388 \\
\hline Duration of treatment, mean (SD), years & $14.4(10.1)$ & $14.7(9.7)$ & 0.858 \\
\hline Body mass index, mean (SD), $\mathrm{kg} / \mathrm{m}^{2}$ & $26.0(4.8)$ & $25.2(4.5)$ & 0.212 \\
\hline Waist circumference, mean (SD), cm & $84.0(11.4)$ & $81.6(10.4)$ & 0.143 \\
\hline \multicolumn{4}{|l|}{ Clinical characteristics } \\
\hline Metabolic syndrome, yes (\%) & $85(36.0)$ & $12(18.2)$ & 0.006 \\
\hline Hypertension, yes (\%) & $79(33.5)$ & $12(18.2)$ & 0.017 \\
\hline Diabetes mellitus, yes (\%) & $120(50.8)$ & $26(39.4)$ & 0.100 \\
\hline Clinical Global Impression, mean (SD) & $3.7(1.1)$ & $3.9(1.2)$ & 0.133 \\
\hline Depressive symptoms, mean (SD) & $6.5(2.9)$ & $6.5(2.6)$ & 0.923 \\
\hline Dosage of antipsychotics, mean (SD), mg & $4.8(4.3)$ & $4.7(3.4)$ & 0.069 \\
\hline Physical activity, mean (SD), METS & $604.1(591.5)$ & $662.3(588.0)$ & 0.491 \\
\hline \multicolumn{4}{|l|}{ Diet habit (SD) } \\
\hline Total score & $41.7(6.7)$ & $42.4(6.7)$ & 0.511 \\
\hline Balanced diet score & $9.9(2.7)$ & $10.3(3.5)$ & 0.325 \\
\hline Regular diet score & $10.5(3.2)$ & $11.1(3.3)$ & 0.158 \\
\hline Healthy and diet score & $21.3(3.3)$ & $20.8(3.4)$ & 0.342 \\
\hline Dairy intake score & $3.6(1.2)$ & $3.8(1.4)$ & 0.244 \\
\hline \multicolumn{4}{|l|}{ Laboratory characteristics } \\
\hline Vitamin D level, mean(SD), ng/mL & $12.8(4.0)$ & $24.8(4.6)$ & $<0.001$ \\
\hline Fasting plasma glucose, mean (SD), mg/dL & $108.3(39.0)$ & $102.5(30.7)$ & 0.276 \\
\hline HbAlc, mean (SD), \% & $5.9(3.5)$ & $5.5(0.74)$ & 0.354 \\
\hline Total cholesterol, mean (SD), mg/dL & $182.6(39.4)$ & $175.1(32.8)$ & 0.158 \\
\hline Triglyceride, mean (SD), mg/dL & $150.6(104.6)$ & $108.8(68.8)$ & 0.002 \\
\hline High-density lipoprotein, mean (SD), mg/dL & $46.1(11.2)$ & $47.8(9.8)$ & 0.278 \\
\hline Low-density lipoprotein, mean (SD), mg/dL & $107.7(33.7)$ & $106.1(29.4)$ & 0.734 \\
\hline AST mean (SD), mg/dL & $24.9(18.1)$ & $22.8(10.1)$ & 0.356 \\
\hline ALT, mean (SD), mg/dL & $29.7(31.6)$ & $22.2(17.0)$ & 0.011 \\
\hline$\gamma$-GTP, mean (SD), mg/dL & $36.1(34.3)$ & $34.4(37.8)$ & 0.732 \\
\hline Blood Urea Nitrogen, mean (SD), mg/dL & $84.1(17.0)$ & $88.0(13.1)$ & 0.094 \\
\hline Creatinine, mean (SD), mg/dL & $1.0(0.5)$ & $1.0(0.1)$ & 0.444 \\
\hline Prolactin, mean (SD), mg/dL & $41.8(43.5)$ & $42.2(50.0)$ & 0.952 \\
\hline
\end{tabular}

Bold font denotes statistical significance. ${ }^{*} \chi^{2}$ test, t-test, or Mann-Whitney $U$ test as appropriate. SD: standard deviation, AST: aspartate aminotransferase, ALT: alanine transaminase, $\gamma$-GTP: gamma-glytamyltransferase 
Table 2. Logistic regression model for association between vitamin $D$ insufficiency and cardiovascular disease

\begin{tabular}{lcccc}
\hline & OR $(95 \% \mathrm{CI})$ & p-value & Adjusted OR* $(95 \%$ CI $)$ & p-value \\
\hline Metabolic syndrome & $2.5(1.3-5.0)$ & 0.007 & $3.1(1.5-6.4)$ & 0.003 \\
Hypertension & $2.3(1.1-4.5)$ & 0.019 & $2.5(1.2-5.3)$ & 0.013 \\
\hline
\end{tabular}

*adjusted for physical activity and dietary habit scores in the model. OR: odds ratio, CI: confidence interval

and illness duration were not different according to vitamin $\mathrm{D}$ insufficiency. Metabolic syndrome and hypertension were significantly more frequent and levels of triglycerides and ALT were significantly higher in patients with a vitamin D insufficiency than in those without a vitamin D insufficiency. Values of other laboratory measures were not different based on the presence of a vitamin D insufficiency. Scores on the CGI, the depression scale, IPAQ, and the dietary questionnaire were also not different according to vitamin D insufficiency.

Table 2 shows the results of the logistic regression analysis. Vitamin D insufficiency was significantly associated with metabolic syndrome and hypertension. After adjusting for physical activity and dietary habit scores, vitamin D insufficiency remained significantly associated with metabolic syndrome and hypertension.

\section{DISCUSSION}

Vitamin D deficiency is considered a major health issue worldwide, although its significance is uncertain. ${ }^{17}$ This also applies to the psychiatric field. ${ }^{3}$ In general medicine, the link between Vitamin D and medical comorbidity has shifted from being seen as causative to being a proxy marker of lifestyle issues, highlighted by the failure of many treatment trials to influence the targeted disorder. ${ }^{26}$ The present study demonstrated that vitamin D insufficiency was highly prevalent (78.1\%) in patients with a psychotic disorder and was associated with metabolic syndrome and hypertension. The high prevalence of vitamin $\mathrm{D}$ insufficiency in our population with a psychotic disorder was compatible with previous studies conducted in western countries. ${ }^{3,27}$ The prevalence of vitamin D insufficiency in this community-dwelling psychotic population was higher than that in the general South Korean population. A recent South Korean study of 17,252 health examinees showed that $60.4 \%$ ( $47.3 \%$ in males and $64.5 \%$ in females) of examinees had a vitamin D insufficiency $(<20 \mathrm{ng} / \mathrm{mL}){ }^{28}$

The prevalence of metabolic syndrome in this study was $32.1 \%$, which is higher than that in the South Korean general population. ${ }^{29,30}$ We also observed that metabolic syndrome components, such as hypertension and high triglyceride, were inversely associated with circulating serum vitamin $\mathrm{D}$ levels. Metabolic syndrome is a very important risk factor for cardiovascular disease, which is a major cause of death and early mortality in patients with psychosis. ${ }^{12,31,32}$ In previous studies of the general population, vitamin D insufficiency was associated with a risk for metabolic syndrome..$^{33-35}$ Vitamin D deficiency is also related to increased risk of hypertension, heart failure, and ischemic disease. ${ }^{10}$ This is the first study to demonstrate an association between vitamin D insufficiency, metabolic syndrome, and hypertension in an Asian population with psychosis.

Several mechanisms have been proposed to explain the association between vitamin D and future risk of metabolic syndrome. Since vitamin D is fat soluble and could be stored in adipose tissue, the levels of circulating vitamin $\mathrm{D}$ can be reduced in the blood of obese individuals. ${ }^{35,36}$ Vitamin D has also been shown to inhibit the release of cytokines from the immune cell. ${ }^{37}$ Another hypothesis is the negative regulatory effect of vitamin $\mathrm{D}$ on renin activity. In an animal study, vitamin D receptor knockout mice had hypertension, cardiac hypertrophy, and increased activation of the renin-angiotensin-aldosterone system. ${ }^{38}$ Mechanism for the association between vitamin $\mathrm{D}$ and cardiovascular risk involves the effect of vitamin $\mathrm{D}$ on improving insulin sensitivity ${ }^{39,40}$ by directly acting on cardiac tissue in response to injury ${ }^{41}$ and vascular compliance and response to injury. ${ }^{42,43}$

As this study was cross-sectional, we cannot conclude that vitamin D insufficiency was the cause of metabolic syndrome or hypertension. In particular, poor physical activity and dietary habits may affect both metabolic syndrome and vitamin D insufficiency because vitamin D is produced in the skin as vitamin $\mathrm{D}_{3}$ through sun exposure or is obtained from the diet as vitamin $\mathrm{D}_{2}$ or $\mathrm{D}_{3 .}{ }^{10}$ In our study, only 66 patients (21.9\%) were moderately or highly physically active as measured by the IPAQ. This is a very low level compared with levels of physical activity measured by the same scale for the general populations in 20 other countries. ${ }^{44}$ Negative symptoms of schizophrenia may be related to low physical activity ${ }^{45}$ and sun exposure, and consequently cause a vitamin D insufficiency. However, in our study, vitamin D level was not different according to physical activity or dietary habits. In addition, the significant association between vitamin D insufficiency and metabolic syndrome remained after adjusting for physical activity and dietary habits.

Although liver function tests including AST and ALT are not diagnostic criteria for metabolic syndrome, liver markers have also been implicated in the development of metabolic syndrome. ${ }^{46} \mathrm{ALT}$ is correlated with increased hepatic fat con- 
tent, which is associated with insulin resistance regardless of body weight. Insulin resistance has detrimental effects on components of metabolic syndrome. ${ }^{47-49}$ Our study showed that patients with a vitamin $\mathrm{D}$ insufficiency were associated with a higher ALT, which indirectly suggests an association between vitamin D insufficiency and metabolic syndrome.

Whether vitamin D supplementation decreases cardiovascular risk in the general population or patients with mental illness is controversial. Several studies have focused on vitamin $\mathrm{D}$ as a potential anti-hypertensive agent, but they have not consistently shown a positive effect. ${ }^{10}$ Very few studies have been performed on whether vitamin D supplementation reduces the risk of cardiovascular mortality. Both the Women's Health Initiative Study ${ }^{50}$ and a European study ${ }^{51}$ showed no improved cardiovascular survival after vitamin D supplementation. On the other hand, a recent meta-analysis examined nine randomized controlled trials and showed an $8 \%$ reduction in all-cause mortality with supplementation of up to $500 \mathrm{IU}$ vitamin D. ${ }^{10}$ That study was conducted on a general population. Although a few studies have analyzed whether vitamin D supplementation affects mental health, with the largest being negative, ${ }^{52}$ no research has been conducted on the influence of vitamin $\mathrm{D}$ supplementation on metabolic syndrome and cardiovascular risk in patients with a psychotic disorder. In addition, there is no consensus on the appropriate vitamin $\mathrm{D}$ dose for patients with a mental illness. Therefore, prospective studies are required to define whether vitamin D supplementation can reduce the occurrence of metabolic syndrome and cardiovascular risk in patients with a psychotic disorder and the appropriate vitamin $\mathrm{D}$ dose needed.

Vitamin D level is associated with various mental health issues. In particular, low vitamin D level is associated with depression. ${ }^{53}$ However, in our study, low vitamin D level was not related to depressive symptoms or the general severity of psychotic symptoms.

This study had several limitations. First, this study was crosssectional, so we were unable to investigate the causal relationship between vitamin D and metabolic syndrome. Second, the assessment of depressive symptoms, dietary habits, and physical activity depended on self-reported data. Third, a formal scale to measure psychotic symptoms was not administerd. Fourth, we did not investigate intake of vitamin supplements. Finally, most of the study population participated in this study during late fall and early winter when vitamin D levels might be lower than at other times of the year. ${ }^{28,54}$ In addition, amount of sun exposure was not investigated.

Nevertheless, this study has important clinical and research implications by showing that vitamin D insufficiency was very prevalent and associated with metabolic syndrome and hypertension in South Korean patients with psychosis. Further longitudinal and interventional studies are required in patients with psychosis.

\section{Acknowledgements}

This research was supported by Basic Science Research Program through the National Research Foundation of Korea (NRF) funded by the Ministry of Education (NRF-2014R1A1A4A01005245). This research work was conducted as part of the Gwangju Mental Health Demonstration Project supported by Ministry of Health \& Welfare and Gwangju Metropolitan city, Republic of Korea.

\section{REFERENCES}

1. Wilkins CH, Sheline YI, Roe CM, Birge SJ, Morris JC. Vitamin D deficiency is associated with low mood and worse cognitive performance in older adults. Am J Geriatr Psychiatry 2006;14:1032-1040.

2. Endres D, Dersch R, Stich O, Buchwald A, Perlov E, Feige B, et al. Vitamin $\mathrm{D}$ deficiency in adult patients with schizophreniform and autism spectrum syndromes: a one-year cohort study at a German tertiary care hospital. Front Psychiatry 2016;7:168.

3. Berk M, Jacka FN, Williams LJ, Ng F, Dodd S, Pasco JA. Is this D vitamin to worry about? Vitamin D insufficiency in an inpatient sample. Aust N Z J Psychiatry 2008;42:874-878.

4. Berk M, Sanders KM, Pasco JA, Jacka FN, Williams LJ, Hayles AL, et al. Vitamin D deficiency may play a role in depression. Med Hypotheses 2007;69:1316-1319.

5. Shukurova M, Yuksek E, Emul M, Savrun M. Vitamin D level in schizophrenia and association with metabolic syndrome parameters. Klinik Psikofarmakol Bülteni 2015;25(Suppl 1):S29-S30.

6. Dogan Bulut S, Bulut S, Gorkem Atalan D, Berkol T, Gurcay E, Turker $\mathrm{T}$, et al. The relationship between symptom severity and low vitamin D levels in patients with schizophrenia. PLoS One 2016;11:e0165284.

7. Liu NH, Daumit GL, Dua T, Aquila R, Charlson F, Cuijpers P, et al. Excess mortality in persons with severe mental disorders: a multilevel intervention framework and priorities for clinical practice, policy and research agendas. World Psychiatry 2017;16:30-40.

8. McGrath JJ, Eyles DW, Pedersen CB, Anderson C, Ko P, Burne TH, et al. Neonatal vitamin D status and risk of schizophrenia: a population-based case-control study. Arch Gen Psychiatry 2010;67:889-894.

9. Melamed ML, Michos ED, Post W, Astor B. 25-hydroxyvitamin D levels and the risk of mortality in the general population. Arch Intern Med 2008;168:1629-1637.

10. Wang TJ, Pencina MJ, Booth SL, Jacques PF, Ingelsson E, Lanier K, et al. Vitamin D deficiency and risk of cardiovascular disease. Circulation 2008;117:503-511.

11. Giovannucci E, Liu Y, Hollis BW, Rimm EB. 25-hydroxyvitamin D and risk of myocardial infarction in men: a prospective study. Arch Intern Med 2008;168:1174-1180.

12. Martens PJ, Chochinov HM, Prior HJ. Where and how people with schizophrenia die: a population-based, matched cohort study in Manitoba, Canada. J Clin Psychiatry 2013;74:e551-e557.

13. Sugai T, Suzuki Y, Yamazaki M, Shimoda K, Mori T, Ozeki Y, et al. High prevalence of obesity, hypertension, hyperlipidemia, and diabetes mellitus in Japanese outpatients with schizophrenia: a nationwide survey. PLoS one 2016;11:e0166429.

14. Dawson-Hughes B. Racial/ethnic considerations in making recommendations for vitamin D for adult and elderly men and women. Am J Clin Nutr 2004;80(6 Suppl):1763S-1766S.

15. Lips P. Vitamin D status and nutrition in Europe and Asia. J Steroid Biochem Mol Biol 2007;103:620-625.

16. Lips P, Hosking D, Lippuner K, Norquist JM, Wehren L, Maalouf G, et al. The prevalence of vitamin $\mathrm{D}$ inadequacy amongst women with osteoporosis: an international epidemiological investigation. J Intern Med 2006;260:245-254. 
17. Mithal A, Wahl DA, Bonjour JP, Burckhardt P, Dawson-Hughes B, Eisman JA, et al. Global vitamin D status and determinants of hypovitaminosis D. Osteoporos Int 2009;20:1807-1820.

18. Leucht S, Samara M, Heres S, Davis JM. Dose equivalents for antipsychotic drugs: the DDD method. Schizophr Bull 2016;42(Suppl 1):S90S94.

19. Haro JM, Kamath SA, Ochoa S, Novick D, Rele K, Fargas A, et al. The Clinical Global Impression-Schizophrenia scale: a simple instrument to measure the diversity of symptoms present in schizophrenia. Acta Psychiatr Scand Suppl 2003;(406):16-23.

20. Radloff LS. The CES-D scale: a self-report depression scale for research in the general population. Appl Psychol Meas 1977;1:385-401.

21. Biernat E, Stupnicki R, Lebiedziński B, Janczewska L. Assessment of physical activity by applying IPAQ questionnaire. J Phys Educ 2008;52: 46-52.

22. The International Physical Activity Questionnaire, 2005. Available at: http://www.ipaq.ki.se/. Accessed November 8, 2005.

23. Korean Ministry of Health and Welfare. Dietary Guidelines for Korean Adults. Seoul: Ministry of Health and Welfare; 2010.

24. Lee SY, Park HS, Kim DJ, Han JH, Kim SM, Cho GJ, et al. Appropriate waist circumference cutoff points for central obesity in Korean adults. Diabetes Res Clin Pract 2007;75:72-80.

25. Pearce SH, Cheetham TD. Diagnosis and management of vitamin D deficiency. BMJ 2010;340:b5664.

26. McGrath JJ. Vitamin D and mental health-the scrutiny of science delivers a sober message. Acta Psychiatr Scand 2017;135:183-184.

27. Menkes DB, Lancaster K, Grant M, Marsh RW, Dean P, du Toit SA. Vitamin D status of psychiatric inpatients in New Zealand's Waikato region. BMC Psychiatry 2012;12:68.

28. Nah EH, Kim S, Cho HI. Vitamin D levels and prevalence of vitamin $\mathrm{D}$ deficiency associated with sex, age, region, and season in Koreans. Lab Med Online 2015;5:84-91.

29. Lim S, Shin H, Song JH, Kwak SH, Kang SM, Won Yoon J, et al. Increasing prevalence of metabolic syndrome in Korea: the Korean National Health and Nutrition Examination Survey for 1998-2007. Diabetes Care 2011;34:1323-1328.

30. Tran BT, Jeong BY, Oh JK. The prevalence trend of metabolic syndrome and its components and risk factors in Korean adults: results from the Korean National Health and Nutrition Examination Survey 2008-2013. BMC Public Health 2017;17:71.

31. Galassi A, Reynolds K, He J. Metabolic syndrome and risk of cardiovascular disease: a meta-analysis. Am J Med 2006;119:812-819.

32. Hennekens CH, Hennekens AR, Hollar D, Casey DE. Schizophrenia and increased risks of cardiovascular disease. Am Heart J 2005;150: 1115-1121.

33. Parker J, Hashmi O, Dutton D, Mavrodaris A, Stranges S, Kandala NB, et al. Levels of vitamin D and cardiometabolic disorders: systematic review and meta-analysis. Maturitas 2010;65:225-236.

34. Ford ES, Ajani UA, McGuire LC, Liu S. Concentrations of serum vitamin D and the metabolic syndrome among US adults. Diabetes Care 2005;28:1228-1230.

35. Al-Dabhani K, Tsilidis KK, Murphy N, Ward HA, Elliott P, Riboli E, et al. Prevalence of vitamin D deficiency and association with metabolic syndrome in a Qatari population. Nutr Diabetes 2017;7:e263.

36. Wortsman J, Matsuoka LY, Chen TC, Lu Z, Holick MF. Decreased bioavailability of vitamin D in obesity. Am J Clin Nutr 2000;72:690-693.

37. Awad AB, Alappat L, Valerio M. Vitamin D and Metabolic syndrome risk factors: evidence and mechanisms. Crit Rev Food Sci Nutr 2012;52: 103-112.

38. Li YC, Kong J, Wei M, Chen Z-F, Liu SQ, Cao LP. 1, 25-Dihydroxyvita$\min \mathrm{D} 3$ is a negative endocrine regulator of the renin-angiotensin system. J Clin Invest 2002;110:229-238.

39. Mathieu C, Gysemans C, Giulietti A, Bouillon R. Vitamin D and diabetes. Diabetologia 2005;48:1247-1257.

40. Norman AW, Frankel J, Heldt AM, Grodsky GM. Vitamin D deficiency inhibits pancreatic secretion of insulin. Science 1980;209:823-825.

41. Tishkoff DX, Nibbelink KA, Holmberg KH, Dandu L, Simpson RU. Functional vitamin D receptor (VDR) in the t-tubules of cardiac myocytes: VDR knockout cardiomyocyte contractility. Endocrinology 2008; 149:558-564.

42. Artaza JN, Norris KC. Vitamin D reduces the expression of collagen and key profibrotic factors by inducing an antifibrotic phenotype in mesenchymal multipotent cells. J Endocrinol 2009;200:207-221.

43. Sugden J, Davies J, Witham M, Morris A, Struthers A. Vitamin D improves endothelial function in patients with Type 2 diabetes mellitus and low vitamin D levels. Diabet Med 2008;25:320-325.

44. Bauman A, Bull F, Chey T, Craig CL, Ainsworth BE, Sallis JF, et al. The International Prevalence Study on Physical Activity: results from 20 countries. Int J Behav Nutr Phys Act 2009;6:21.

45. Vancampfort D, Knapen J, Probst M, Scheewe T, Remans S, De Hert M. A systematic review of correlates of physical activity in patients with schizophrenia. Acta Psychiatr Scand 2012;125:352-362.

46. Hanley AJ, Williams K, Festa A, Wagenknecht LE, D’Agostino RB, Haffner SM. Liver markers and development of the metabolic syndrome. Diabetes 2005;54:3140-3147.

47. Browning JD, Szczepaniak LS, Dobbins R, Horton JD, Cohen JC, Grundy SM, et al. Prevalence of hepatic steatosis in an urban population in the United States: impact of ethnicity. Hepatology 2004;40:1387-1395.

48. Seppälä-Lindroos A, Vehkavaara S, Häkkinen AM, Goto T, Westerbacka J, Sovijärvi A, et al. Fat accumulation in the liver is associated with defects in insulin suppression of glucose production and serum free fatty acids independent of obesity in normal men. J Clin Endocrinol Metab 2002;87:3023-3028.

49. Bugianesi E, Gastaldelli A, Vanni E, Gambino R, Cassader M, Baldi S, et al. Insulin resistance in non-diabetic patients with non-alcoholic fatty liver disease: sites and mechanisms. Diabetologia 2005;48:634-642.

50. LaCroix AZ, Kotchen J, Anderson G, Brzyski R, Cauley JA, Cummings $\mathrm{SR}$, et al. Calcium plus vitamin D supplementation and mortality in postmenopausal women: the Women's Health Initiative calcium-vitamin D randomized controlled trial. J Gerontol A Biol Sci Med Sci 2009; 64:559-567.

51. Trivedi DP, Doll R, Khaw KT. Effect of four monthly oral vitamin D3 (cholecalciferol) supplementation on fractures and mortality in men and women living in the community: randomised double blind controlled trial. BMJ 2003;326:469.

52. Sanders KM, Stuart AL, Williamson EJ, Jacka FN, Dodd S, Nicholson G, et al. Annual high-dose vitamin D3 and mental well-being: randomised controlled trial. Br J Psychiatry 2011;198:357-364.

53. Anglin RE, Samaan Z, Walter SD, McDonald SD. Vitamin D deficiency and depression in adults: systematic review and meta-analysis. Br J Psychiatry 2013;202:100-107.

54. Klingberg E, Olerod G, Konar J, Petzold M, Hammarsten O. Seasonal variations in serum 25-hydroxy vitamin D levels in a Swedish cohort. Endocrine 2015;49:800-808. 